\title{
A Novel Disjunctive Model for the Simultaneous Optimization and Heat Integration
}

\author{
Natalia Quirante ${ }^{\mathrm{a}}$, José A. Caballero ${ }^{\mathrm{a}, *}$ and Ignacio E. Grossmann ${ }^{\mathrm{b}}$. \\ ${ }^{\text {a }}$ Institute of Chemical Processes Engineering. University of Alicante, PO 99, E-03080 Alicante, Spain. \\ ${ }^{\mathrm{b}}$ Department of Chemical Engineering. Carnegie Mellon University, 5000 Forbes Ave., Pittsburgh, PA 15213, \\ USA. \\ *Corresponding author: caballer@ua.es, Tel: +34 965902322. Fax: +34 965903826.
}

E-mail addresses: natalia.quirante@ua.es (N. Quirante), caballer@ua.es (J.A. Caballero), grossmann@cmu.edu (I.E. Grossmann)

\begin{abstract}
This paper introduces a new disjunctive formulation for the simultaneous optimization and heat integration of systems with variable inlet and outlet temperatures in process streams as well as the possibility of selecting and using different utilities. The starting point is the original compact formulation of the Pinch Location Method, however, instead of approximating the "maximum" operator with smooth, but non-convex functions, these operators are modeled by means of a disjunction. The new formulation has shown to have equal or lower relaxation gap than the best alternative reformulation, thus reducing computational time and numerical problems related to non-convex approximations.
\end{abstract}

Keywords: heat integration, variable temperatures, disjunctive model, simultaneous optimization.

\section{Introduction}

An important factor in determining the optimal design of a chemical process is heat integration because energy consumption contributes significantly to the total cost of a process. Therefore, minimizing energy consumption, minimizing energy losses, and increasing the energy efficiency increases the efficiency and the economic benefits of a chemical plant.

The most important technique to decrease energy consumption is through the implementation of heat exchanger networks. The concept of heat integration making the concept of pinch analysis was introduced in 1978 by Linnhoff and Flower (1978). The idea was based on determining the minimum utility requirements of a process, and identifying the maximum possible grade of heat recovery as a function of the minimum temperature difference inside the heat exchanger network. In 1983, Linhoff and Hindmarsh (1983) showed that it is possible to save a significant part of the energy required by a plant.

A detailed review of heat integration and heat integration alternatives is out of the scope of this paper. A simple search using the Scopus Database (SCOPUS Database, 2016) using the keywords «Heat Integration» yields more than 5400 results in just the last 5 years, and more than 1100 in the specific area of Chemical Engineering. Comprehensive information about the initial advances after the pinch introduction can be found in the reviews by Gundersen and Naess (1988) or Jezowski (1994a, 1994b). A comprehensive review with annotated bibliography that covers all the advances in the $20^{\text {th }}$ century was due to Furman and Sahinidis (2002). A general overview of the state of the art at the end of $20^{\text {th }}$ century in process engineering including heat integration can be found in the work by Grossmann et al. (1999) or Dunn and El-Halwagi (2003). More recent reviews including the most relevant advances in the last years are those by Morar and Agachi (2010), and Klemeš and Kravanja (2013). With the focus on heat exchanger networks retrofit, the recent review by Sreepathi and Rangaiah (2014) is also interesting. The importance of process integration in general and the combination of Heat Integration with some particular subsystems has also received considerable attention. For example, Ahmetovic reviewed the literature for water and energy integration (Ahmetović et al., 2015; Ahmetović \& Kravanja, 2013). Wechsung et al. (2011) and Onishi et al. (2014a) introduced the concept of heat and mechanical power integration. Fernández et al. (2012) presented a comprehensive review of energy integration in batch processes, Quirante and Caballero 
(2016) proposed the simultaneous optimization, heat integration, and life cycle assessment (LCA) for the optimization of a very large scale sour water stripping plant.

A heat integrated flowsheet can be obtained using mainly two different approaches: Sequential or simultaneous strategy. In the first stage of the sequential strategy, the process configuration and the operating conditions are optimized assuming that all heating and cooling needs are supplied by utilities. In the second stage, with the information of the optimal stream conditions, heat integration is performed and the heat exchanger network (HEN) is designed (Ahmad et al., 1990; Linhoff \& Hindmarsh, 1983; Linnhoff, 1993; Linnhoff \& Ahmad, 1990).

In the simultaneous strategy, the heat integration and the flowsheet synthesis are performed simultaneously. Some works have demonstrated that the simultaneous optimization and heat integration can achieve important savings in the total cost of a process, compared to the sequential strategy (Duran \& Grossmann, 1986; Lang et al., 1988). In problems with specific characteristics like some subsystems or in small or medium size problems (Caballero \& Grossmann, 2006; Onishi et al., 2014b) it is possible to use a superstructure (Yee \& Grossmann, 1990; Yee et al., 1990) and simultaneously obtaining the optimal operating conditions and the heat exchanger network. However, in large problems the size of the model is so large that usually it cannot be solved with the state of the art NLP/MINLP solvers. However, in many cases, the energy costs dominate the investment costs or we expect that for a given minimum energy consumption target, the investment in the different alternatives do not have an important influence in the optimal operating conditions of the optimized flowsheet. In other words, we simultaneously optimize the operating conditions and the energy consumption but without considering the actual structure of the heat exchanger network. The information required to predict the minimum energy target for a given set of hot and cold streams can be obtained from the "Problem Table" (Linnhoff, 1993) or using the transshipment model (Papoulias \& Grossmann, 1983). In both approaches, it is necessary to introduce the concept of «Temperature intervals». This is adequate for 'a posteriori' heat integration or if the optimization is performed using a derivative-free solver (Corbetta et al., 2016). However, the state of the art gradient based NLP/MINLP solvers require smooth functions. If the process stream temperatures are not constant some temperature intervals can disappear or other news can appear, which mathematically translates into discontinuities, and therefore into points of non-differentiability.

To overcome the numerical difficulties related to the temperature intervals, Duran and Grossmann (1986) presented the «Pinch Location Method» (PLM). The next section presents an overview of PLM. Even though the PLM does not rely on the temperature interval concept, the final model includes the "maximum" operator that introduces non-differentiabilities. In the original work, Duran and Grossmann proposed to approximate the max operator with smooth functions. This approach avoids the non-differentiability problem, and reduces the problem into an NLP. However, the smooth approximation is non-convex and its numerical behavior depends on parameters in the approximation function. Later, Grossmann et al. (1998) presented a disjunctive model that overcomes all previous limitations at the cost of introducing integer variables. Alternatively, Navarro-Amorós et al. (2013) presented an MI(N)LP model that maintains the concept of temperature interval. They assumed a maximum number of temperature intervals and dynamically assign process temperatures to each interval. The numerical test presented by the authors showed that the numerical performance is similar to the disjunctive formulation of the PLM. However, the number of constraints and binary variables can be orders of magnitude larger.

In the rest of the paper we first present and overview of the Pinch Location Method. Then we introduce a novel disjunctive reformulation that has better relaxation gap than the disjunctive model presented by Grossmann et al. (1998) and a similar number of variables and equations. A set of numerical test illustrates the performance of the novel approach in examples with different complexity. Finally, we finish with some conclusions.

\section{The pinch location method. Overview}

In the following paragraphs, we present an overview of the Pinch Location Method. It does not pretend to be a comprehensive description. Notwithstanding, the novel disjunctive formulation is based on it and we consider of 
interest to introduce the more relevant aspects. For further details, the interested reader is referred to the original work (Duran \& Grossmann, 1986).

The pinch analysis assumes that the heat flow of a process stream can be considered constant. If this is not the case in the entire range of temperatures then it is possible to approximate the process streams by different streams with constant heat flows (piecewise linear approximation). Under these conditions, the pinch point occurs always at the inlet temperature of a process stream. Duran and Grossmann (1986) observed that for a given Heat Recovery Approach Temperature (HRAT or $\Delta \mathrm{T}_{\min }$ ), if we check all the candidate to pinch point temperatures, the correct one is the temperature with the largest heating and cooling utilities among all the candidates. Fig. 1 with data from Table 1 shows an illustrative example.

Table 1. Stream data for example.

\begin{tabular}{lrrr}
\hline Streams & Tin $\left({ }^{\circ} \mathrm{C}\right)$ & Tout $\left({ }^{\circ} \mathrm{C}\right)$ & $\mathrm{F}\left(\mathrm{kW} /{ }^{\circ} \mathrm{C}\right)$ \\
\hline H1 (hot) & 170 & 70 & 3.0 \\
H2 (hot) & 150 & 70 & 1.5 \\
C1 (cold) & 80 & 140 & 4.0 \\
C2 (cold) & 60 & 170 & 2.0 \\
\hline
\end{tabular}

$\Delta \mathrm{T}_{\min }=20^{\circ} \mathrm{C}$

<Insert Fig. 1>

Fig. 1. Utilities needed for different pinch stream candidates (- Hot - - - Cold). (a) Pinch candidate H1. (b) Pinch candidate H2. (c) Pinch candidate C1. (d) Pinch candidate C2.

Mathematically, the previous result can be written as follows:

$$
\begin{aligned}
Q_{H} & =\max _{p \in P}\left(Q_{H}^{p}\right) \\
Q_{C} & =\max _{p \in P}\left(Q_{C}^{p}\right)
\end{aligned}
$$

Where $P$ is the index set of all the hot and cold process streams (pinch candidates). $i=1 \ldots n_{H}, j=1 \ldots n_{C}$; and $Q_{H}^{p}, Q_{C}^{p}$ are the heating and cooling utilities required from each pinch candidate. Using an energy balance, Eq.

(1) can be written in terms only of heating (or cooling) utilities:

$$
Q_{C}=\Omega+Q_{H}
$$

Where $\Omega$ is the total heat surplus.

$$
\Omega=\sum_{i \in H o t} F_{i}\left(T_{i}^{i n}-T_{i}^{o u t}\right)-\sum_{j \in \text { Cold }} f_{j}\left(t_{j}^{\text {out }}-t_{j}^{\text {in }}\right)
$$

At this point is very important to note that all the temperatures are "shifted temperatures":

$$
\begin{aligned}
& T_{i}^{i n}=\operatorname{Tin}_{i}-\frac{\Delta T_{\min }}{2} \\
& \left.T_{i}^{\text {out }}=\text { Tout }_{i}-\frac{\Delta T_{\text {min }}}{2}\right\} i \text { is a hot stream } \\
& t_{j}^{i n}=\operatorname{tin}_{j}+\frac{\Delta T_{\min }}{2} \\
& \left.t_{j}^{\text {out }}=\text { tout }_{j}+\frac{\Delta T_{\min }}{2}\right\}
\end{aligned}
$$




$$
T^{p}\left\{\begin{array}{c}
T_{i}^{i n}-\frac{\Delta T_{\min }}{2} \text { if } p \text { is a hot stream } i \\
t_{j}^{i n}+\frac{\Delta T_{\min }}{2} \text { if } p \text { is a cold stream } j
\end{array}\right\}
$$

where Tin, Tout, tin, tout are the actual stream process temperatures. Note that $T^{p}$ is also referred to the shifted scale.

From Eq. (1) and (2), the criterion for the pinch location reduces to:

$$
\begin{aligned}
& Q_{H}=\max _{p \in P}\left(Q_{H}^{p}\right) \\
& Q_{C}=\Omega+Q_{H}
\end{aligned}
$$

It is still necessary to get an explicit equation to calculate the term $Q_{H}^{p}$ for each pinch candidate in terms of heat flows and temperatures.

Duran and Grossmann (1986) noted that in order to calculate $Q_{H}^{p}$ it is necessary to take into account only the process streams above the pinch because there is not net heat transfer across the pinch. Therefore, considering an energy balance above the pinch we can write:

$$
Q_{H}^{p}=Q A_{C}^{p}-Q A_{H}^{p}
$$

where $Q A_{C}^{p}$ and $Q A_{H}^{p}$ are the total cold and heat content, respectively, above the pinch of the process.

To calculate $Q A_{H}^{p}$ (or $Q A_{C}^{p}$ ) in terms of heat flows and temperatures, we only need to calculate the contribution of each hot (or cold) stream above the pinch.

For example, for a hot stream $i$ :

- If the inlet and outlet temperatures are greater than the inlet temperature of the pinch candidate $p$ $\left(T_{i}^{\text {in }} \geq T_{i}^{\text {out }} \geq T^{p}\right)$ then the heat content above the pinch is $F_{i}\left(T_{i}^{\text {in }}-T_{i}^{\text {out }}\right)$.

- If the stream crosses the pinch $\left(T_{i}^{\text {in }} \geq T^{p} \geq T_{i}^{\text {out }}\right)$ then the heat content above the pinch is $F_{i}\left(T_{i}^{\text {in }}-\right.$ $\left.T^{p}\right)$.

- If the stream is below the pinch $\left(T^{p} \geq T_{i}^{\text {in }} \geq T_{i}^{\text {out }}\right)$ then there is no heat content above the pinch.

Duran and Grossmann (1986) showed that the following expression captures the three cases:

$$
Q A_{i}^{p}=F_{i}\left[\max \left(0, T_{i}^{\text {in }}-T^{p}\right)-\max \left(0, T_{i}^{\text {out }}-T^{p}\right)\right]
$$

Following a similar approach, the heat content above the pinch for a cold stream $j$ can be calculated by the following expression:

$$
Q A_{j}^{p}=f_{j}\left[\max \left(0, t_{j}^{\text {out }}-T^{p}\right)-\max \left(0, t_{j}^{\text {in }}-T^{p}\right)\right]
$$

Note that lower case letters are used for cold streams and capital letters for hot streams.

The final model for the simultaneous optimization and heat integration can then be written as follows:

$\min f(x)+C_{H} Q_{H}+C_{C} Q_{C}$

s.t. $h(x)=0$

$$
\begin{aligned}
& g(x) \leq 0 \\
& \begin{array}{l}
Q_{H} \geq \sum_{j \in \text { Cold }} f_{j}\left[\max \left(0, t_{j}^{\text {out }}-T^{p}\right)-\max \left(0, t_{j}^{\text {in }}-T^{p}\right)\right] \\
\quad-\sum_{i \in \text { Hot }} F_{i}\left[\max \left(0, T_{i}^{\text {in }}-T^{p}\right)-\max \left(0, T_{i}^{\text {out }}-T^{p}\right)\right] \quad p \in P \\
Q_{C}=Q_{H}+\sum_{i \in \text { Hot }} F_{i}\left(T_{i}^{\text {in }}-T_{i}^{\text {out }}\right)-\sum_{j \in \text { Cold }} f_{j}\left(t_{j}^{\text {out }}-t_{j}^{\text {in }}\right)
\end{array}
\end{aligned}
$$




$$
Q_{H}, Q_{C}, F_{i}, f_{j} \geq 0
$$

\section{Pinch location method. Disjunctive formulation}

The formulation in Eq. (9) has the difficulty of the presence of ' $m a x$ ' operators that are non-differentiable. Duran and Grossmann (1986) proposed to use a smooth approximation (see also (Balakrishna \& Biegler, 1992)). In that case, the model can be solved using state-of-the-art NLP solvers. The major problem with this approach is that the smooth approximations are highly non-convex and depend on at least one small parameter, which must be fixed by the user, and eventually can also introduce numerical conditioning problems.

To solve all the previous drawbacks, Grossmann et al. (1998) proposed a disjunctive formulation.

The basic idea is to explicitly take into account for each combination of process stream with pinch candidate the three possibilities: the stream is above the pinch, it crosses the pinch or it is below the pinch. The model also takes explicitly into account isothermal streams. The model was solved as an MI(N)LP model using a big-M reformulation. If the stream heat flows $\left(F_{i}, f_{j}\right)$ are constant, the resulting model (at least the part related with the heat integration) is linear and can be easily added to any flowsheet model.

In this paper, instead of explicitly dealing with the positions of the different streams in relation to the pinch, we use a disjunction to deal directly with the 'max' operators in the model. Let us first consider the disjunctive model of the following expression and its reformulation to an MILP model using the hull reformulation:

$$
\phi=\max \left(0, c^{T} x\right)
$$

In Eq. (10) $\boldsymbol{c}$ is a vector of known coefficients and $\boldsymbol{x}$ is a vector of variables. An equivalent disjunctive formulation for the previous equation can be written as follows:

$$
\begin{aligned}
& {\left[\begin{array}{c}
Y \\
c^{T} x \geq 0 \\
\phi=c^{T} x \\
\underline{x} \leq x \leq \bar{x}
\end{array}\right] \mathrm{V}\left[\begin{array}{c}
\neg Y \\
c^{T} x \leq 0 \\
\phi=0 \\
x \leq x \leq \bar{x}
\end{array}\right]} \\
& Y \in\{\text { True, False }\}
\end{aligned}
$$

If the Boolean variable takes the value «True» the first term in the disjunction is enforced and $\phi$ must be positive, otherwise $\phi$ is equal to zero.

The hull reformulation (Grossmann \& Trespalacios, 2013) of the previous model -Eq. (11)- is as follows:

$$
\begin{array}{cc} 
& x=x_{1}+x_{2} \\
& \phi=\phi_{1}+\phi_{2} \\
c^{T} x_{1} \geq 0 & c^{T} x_{2} \leq 0 \\
\phi_{1}=c^{T} x_{1} & \phi_{2}=0 \\
y \underline{x} \leq x_{1} \leq y \bar{x} & (1-y) \underline{x} \leq x_{2} \leq(1-y) \bar{x}
\end{array}
$$

The model in Eq. (12) introduces new variables and equations. However, this formulation can be simplified taking into account that:

- Variable $\phi_{2}$ is fixed to zero and, therefore, it can be removed.

- The particular value of the $x_{2}$ variables is not relevant to the problem (they are not used in the model). It is possible then to lump the term $c^{T} x_{2}$ in a single variable:

$$
s=-c^{T} x_{2} ; \quad s \geq 0
$$

$$
\text { The minus sign is only to force the variable } s \text { to be non-negative. }
$$


The hull reformulation of the disjunctive model in Eq. (16) yields the equations in Eq. (15).

Taking all the previous equations into account, the final model for the simultaneous optimization and heat

- It is possible to write the model given in Eq. (12) in terms of the original variables $x$ and the new variable $s$, without defining new variables. To that end, we multiply the first equation in Eq. (12) by the coefficients $c$ and remove variables $x_{1}$ and $x_{2}$ :

$x=x_{1}+x_{2} \quad \rightarrow \quad c^{T} x=c^{T} x_{1}+c^{T} x_{2} \quad \rightarrow \quad c^{T} x=c^{T} x_{1}-s \quad \rightarrow \quad c^{T} x_{1}=c^{T} x+s$

- The last equations in Eq. (12) that force the variables to be zero if the binaries are zero, can be written in terms of the original $x$ and $s$ variables.

The final hull reformulation can then be written as follows:

$$
\begin{aligned}
& \phi=c^{T} x+s \\
& y \phi^{L O} \leq \phi \leq y \phi^{U P} \\
& (1-y) s^{L O} \leq s \leq(1-y) s^{U P} \\
& s \geq 0 ; \phi \geq 0
\end{aligned}
$$

Note that good upper and lower bounds for the $s$ and $\phi$ variables can be easily obtained from the bounds of $x$ variables and $c$ values.

It is interesting to note that the Eq. (15) can also be obtained from the "max" operator formulated as an optimization problem with complementarity constrains (Biegler, 2010), and re-writing the complementarity constraint as a disjunction (or in terms of binary variables).

$$
\phi=\max \left(0, c^{T} x\right) \Rightarrow\left\{\begin{array}{c}
\phi=c^{T} x+s \quad \begin{array}{c}
\phi=c^{T} x+s \\
0 \leq \phi \perp s \geq 0
\end{array} \Rightarrow\left[\begin{array}{c}
Y \\
s=0
\end{array}\right] \vee\left[\begin{array}{c}
\neg Y \\
\phi=0
\end{array}\right] \\
s \geq 0 ; \quad \phi \geq 0
\end{array}\right.
$$




$$
\begin{aligned}
& \min f(x)+C_{H} Q_{H}+C_{C} Q_{C} \\
& \text { s.t. } h(x)=0 \\
& g(x) \leq 0 \\
& Q_{C}=Q_{H}+\sum_{i \in \text { Hot }} F_{i}\left(T_{i}^{\text {in }}-T_{i}^{\text {out }}\right)-\sum_{j \in \text { Cold }} f_{j}\left(t_{j}^{\text {out }}-t_{j}^{\text {in }}\right) \\
& Q_{H} \geq \sum_{j \in \text { Cold }} f_{j}\left[\phi t_{j, p}^{\text {out }}-\phi t_{j, p}^{i n}\right]-\sum_{i \in \text { Hot }} F_{i}\left[\phi T_{i, p}^{\text {in }}-\phi T_{i, p}^{\text {out }}\right] \quad p \in P \\
& \phi t_{j, p}^{\text {out }}=t_{j}^{\text {out }}-T^{p}+s t_{j, p}^{\text {out }} \quad j \in \text { Cold; } p \in P \\
& \phi t_{j, p}^{i n}=t_{j}^{i n}-T^{p}+s t_{j, p}^{i n} \quad j \in \text { Cold } ; p \in P \\
& \phi T_{i, p}^{i n}=T_{i}^{i n}-T^{p}+s T_{i, p}^{i n} \quad i \in H o t ; p \in P \\
& \phi T_{i, p}^{\text {out }}=T_{i}^{\text {out }}-T^{p}+s T_{i, p}^{\text {out }} \quad i \in \text { Hot; } p \in P \\
& s t_{j, p}^{i n} \leq \max \left(0,-\underline{t_{j}^{i n}}+\overline{T^{p}}\right)\left(1-y c_{j}^{i n}\right) \\
& \phi t_{j, p}^{i n} \leq \max \left(0, \overline{t_{j}^{i n}}-\underline{T^{p}}\right) y c_{j}^{i n} \\
& s t_{j, p}^{\text {out }} \leq \max \left(0,-\underline{t_{j}^{\text {out }}}+\overline{T^{p}}\right)\left(1-y c_{j}^{\text {out }}\right) \\
& \phi t_{j, p}^{\text {out }} \leq \max \left(0, \overline{t_{j}^{\text {out }}}-\underline{T^{p}}\right) y c_{j}^{\text {out }} \\
& s T_{i, p}^{i n} \leq \max \left(0,-\underline{T_{i}^{i n}}+\overline{T^{p}}\right)\left(1-y h_{i}^{i n}\right) \\
& \phi T_{i, p}^{i n} \leq \max \left(0, \overline{T_{i}^{i n}}-\underline{T^{p}}\right) y h_{i}^{i n} \\
& s T_{i, p}^{\text {out }} \leq \max \left(0,-\underline{T_{i}^{\text {out }}}+\overline{T^{p}}\right)\left(1-y h_{i}^{\text {out }}\right) \\
& \phi T_{i, p}^{\text {out }} \leq \max \left(0, \overline{T_{i}^{\text {out }}}-\underline{T^{p}}\right) y h_{i}^{\text {out }} \\
& Q_{H}, Q_{C} \geq 0 \\
& F_{i}, \phi T_{i, p}^{\text {in }}, \phi T_{i, p}^{\text {out }}, s T_{i, p}^{\text {in }}, s T_{i, p}^{\text {out }} \geq 0 \quad i \in H o t ; \quad p \in P \\
& f_{j}, \phi t_{j, p}^{i n}, \phi t_{j, p}^{\text {out }}, s t_{j, p}^{\text {in }}, s t_{j, p}^{\text {out }} \geq 0 \quad j \in \text { Cold } ; p \in P \\
& y c_{j}^{\text {in }}, y c_{j}^{\text {out }} \in\{0,1\} j \in \text { Cold } ; p \in P \\
& y h_{i}^{\text {in }}, y h_{i}^{\text {out }} \in\{0,1\} i \in \text { Hot } ; p \in P
\end{aligned}
$$

In the previous model, the set Hot makes reference to the hot streams, the set Cold to the cold streams. The variables $s t, s T$ are equivalent to the ' $s$ ' variable in Eq. (15) and $\phi t, \phi T$ are equivalent to the $\phi$ variable in Eq. (15). The lower bound of a variable is indicated by a line under that variable, and an upper bound by a line over the variable. Variables $y c$ and $y h$ are binary variables related to each one of the max operators in the model.

Some final remarks: Based on the bounds of $s t, s T$ and $\phi t, \phi T$ variables, it is possible to fix a priori some variables. For example if:

$$
-t_{j}^{i n}+\overline{T^{p}} \leq 0 \text { then } s t_{j, p}^{i n}=0 \text { and } y c_{j}^{i n}=1
$$

The novel disjunctive reformulation has fewer Boolean (binary) variables that the disjunctive version presented by Grossmann et al. (1998). The disjunctive formulation proposed by Grossmann et al. (1998) introduces 3 Boolean variables for each combination of hot or cold streams and pinch candidate (the stream is above, crosses 
or is under the pinch candidate). In contrast, in the present model only two binary variables are needed for each process stream pinch candidate. The total number of binary variables is then:

$$
\begin{aligned}
& \text { \#Binaries (Grossmann et al. }(1998))=\left(3 n_{H}+3 n_{C}\right)\left(n_{H}+n_{C}\right)=3\left(n_{H}+n_{C}\right)^{2} \\
& \text { \#Binaries (Present work) }=\left(2 n_{H}+2 n_{C}\right)\left(n_{H}+n_{C}\right)=2\left(n_{H}+n_{C}\right)^{2}
\end{aligned}
$$

However, the total number of variables is larger, because we must add the ' $s$ ' variables. But, the total number of constraints is also lower in the new formulation.

Notwithstanding, the most relevant aspect is that the numerical test shows that the new formulation has always smaller relaxation gaps than the original Grossmann et al. (1998) model.

\subsection{Extension to isothermal streams and multiple utilities}

The inclusion in the model of isothermal streams can be done with at least two different approaches. The first one consists of using a fictitious $1^{\circ} \mathrm{C}$ of variation and calculating the equivalent heat flow assuming that 'dummy' temperature variation. In the second one, we maintain the isothermal condition of the stream. Then the heat added or removed to or from the system can be calculated as:

$$
Q_{\text {isothermal }}=\lambda m
$$

where $\lambda$ is the specific heat associated with the change of phase, and $m$ is the mass flow rate of the stream. An isothermal stream cannot cross the pinch, therefore to calculate the heat content above the pinch $(Q A)$ of the isothermal stream, we can use the following disjunction:

$$
\left[\begin{array}{c}
Y^{i s o} \\
Q A^{i s o}=\lambda m \\
T^{i s o} \geq T^{p}
\end{array}\right] \vee\left[\begin{array}{c}
\neg Y^{i s o} \\
Q A^{i s o}=0
\end{array}\right]
$$

where $Y^{\text {iso }}$ is a Boolean variable that takes the value of True if the temperature of the isothermal stream is greater than the pinch candidate temperature. The hull reformulation of the previous disjunction is as follows:

$$
\begin{aligned}
& Q A^{i s o}=\lambda m \cdot y^{i s o} \\
& T^{p}-T^{i s o} \leq\left(\overline{T^{p}}-\underline{T^{i s o}}\right) y^{i s o}
\end{aligned}
$$

The final model considering isothermal streams can be written as follows:

$$
\begin{aligned}
& \min f(x)+C_{H} Q_{H}+C_{C} Q_{C} \\
& \text { s.t. } h(x)=0 \\
& g(x) \leq 0 \\
& Q_{C}=Q_{H}+\sum_{i \in H o t} F_{i}\left(T_{i}^{\text {in }}-T_{i}^{\text {out }}\right)+\sum_{i \in \text { Hiso }} \lambda_{i} m_{i}-\sum_{j \in \text { Cold }} f_{j}\left(t_{j}^{\text {out }}-t_{j}^{\text {in }}\right)-\sum_{j \in \text { Ciso }} \lambda_{j} m_{j} \\
& Q_{H} \geq \sum_{j \in \text { Cold }} f_{j}\left[\phi t_{j, p}^{o u t}-\phi t_{j, p}^{i n}\right]+\sum_{j \in C i s o} \lambda_{j} m_{j} y c_{j}^{i s o} \\
& -\sum_{i \in H o t} F_{i}\left[\phi T_{i, p}^{i n}-\phi T_{i, p}^{o u t}\right]-\sum_{i \in H i s o} \lambda_{i} m_{i} y h_{i}^{i s o} \quad p \in P \\
& T^{p}-T_{i}^{i s o} \leq\left(\overline{T^{p}}-\underline{T_{i}^{i s o}}\right) y h_{i}^{i s o} \quad p \in P ; i \in \text { Hiso } \\
& T^{p}-t_{j}^{i s o} \leq\left(\overline{T^{p}}-\underline{t_{j}^{i s o}}\right) y c_{j}^{i s o} \quad p \in P ; j \in \text { Ciso } \\
& \phi t_{j, p}^{\text {out }}=t_{j}^{\text {out }}-T^{p}+s t_{j, p}^{\text {out }} \quad j \in \text { Cold } ; p \in P \\
& \phi t_{j, p}^{i n}=t_{j}^{i n}-T^{p}+s t_{j, p}^{i n} \quad j \in \text { Cold; } p \in P
\end{aligned}
$$




$$
\begin{aligned}
& \phi T_{i, p}^{i n}=T_{i}^{i n}-T^{p}+s T_{i, p}^{i n} \quad i \in H o t ; p \in P \\
& \phi T_{i, p}^{\text {out }}=T_{i}^{\text {out }}-T^{p}+s T_{i, p}^{\text {out }} \quad i \in \text { Hot } ; p \in P \\
& s t_{j, p}^{i n} \leq \max \left(0,-\underline{t_{j}^{i n}}+\overline{T^{p}}\right)\left(1-y c_{j}^{i n}\right) \\
& \phi t_{j, p}^{i n} \leq \max \left(0, \overline{t_{j}^{i n}}-\underline{T^{p}}\right) y c_{j}^{i n} \\
& s t_{j, p}^{\text {out }} \leq \max \left(0,-\underline{t_{j}^{\text {out }}}+\overline{T^{p}}\right)\left(1-y c_{j}^{\text {out }}\right) \\
& \phi t_{j, p}^{\text {out }} \leq \max \left(0, \overline{t_{j}^{\text {out }}}-\underline{T^{p}}\right) y c_{j}^{\text {out }} \\
& s T_{i, p}^{i n} \leq \max \left(0,-\underline{T_{i}^{i n}}+\overline{T^{p}}\right)\left(1-y h_{i}^{i n}\right) \\
& \phi T_{i, p}^{i n} \leq \max \left(0, \overline{T_{i}^{i n}}-\underline{T^{p}}\right) y h_{i}^{i n} \\
& s T_{i, p}^{\text {out }} \leq \max \left(0,-\underline{T_{i}^{\text {out }}}+\overline{T^{p}}\right)\left(1-y h_{i}^{\text {out }}\right) \\
& \phi T_{i, p}^{\text {out }} \leq \max \left(0, \overline{T_{i}^{\text {out }}}-\underline{T^{p}}\right) y h_{i}^{\text {out }} \\
& Q_{H}, Q_{C} \geq 0 \\
& F_{i}, \phi T_{i, p}^{\text {in }}, \phi T_{i, p}^{\text {out }}, s T_{i, p}^{\text {in }}, s T_{i, p}^{\text {out }} \geq 0 \quad i \in H o t ; p \in P \\
& f_{j}, \phi t_{j, p}^{\text {in }}, \phi t_{j, p}^{\text {out }}, s t_{j, p}^{\text {in }}, s t_{j, p}^{\text {out }} \geq 0 \quad j \in \text { Cold } ; p \in P \\
& y c_{j}^{i n}, y c_{j}^{\text {out }} \in\{0,1\} j \in \text { Cold } ; p \in P \\
& y h_{i}^{\text {in }}, y h_{i}^{\text {out }} \in\{0,1\} i \in H o t ; p \in P
\end{aligned}
$$

Note that in Eq. (22) the sets Hot and Cold make reference to the non-isothermal process streams, and the sets Hiso and Ciso refer to the hot and cold isothermal streams.

The introduction of multiple utilities is straightforward. In this case, the inlet and outlet temperatures are known and the variable is the heat flow $(f$ or $F$ ) in non-isothermal streams and the mass flowrate in the case of isothermal streams.

\section{Case studies: Heat integration examples}

In this paper, a series of examples are presented to illustrate the performance of the method. Examples include: fixed and variable stream temperatures (MILP); variable stream temperatures with a penalty function that simulates the behavior of a system; simultaneous process optimization and heat integration using a hybrid simulation-optimization approach, where the flowsheet is solved by a commercial process simulator, and the heat integration model is in equation form; and variable stream temperatures with addition of multiple utilities.

Calculations of fixed and variable stream temperature problems were carried out in GAMS (Rosenthal, 2012).

Calculations of the simultaneous process optimization and heat integration problem were performed in TOMLAB-MATLAB (Holmström, 1999) and the simulations were performed on Aspen HYSYS v.8.4. (Hyprotech, 1995 - 2011). The computations were performed in a computer with a $3.60 \mathrm{GHz}$ Intel ${ }^{\circledR} \mathrm{Core}^{\mathrm{TM}}$ i7 Processor and 8 GB of RAM under Windows 7.

All the problems were solved for a minimum heat recovery approach temperature $\left(\Delta T_{\min }\right)$ of $10^{\circ} \mathrm{C}$.

\subsection{Case study 1: Process with fixed stream conditions (MILP)}


The first example solved (test problem 1) consists of a problem in which heat flow rates, and inlet and outlet temperatures are known and constant. The objective consists of determining the minimum utility costs. This problem has to be solved as a mixed integer linear problem (MILP) because it includes continuous and binary variables and all the model equations are linear. Data corresponding to test problem 1 are shown in Table 2.

Table 2. Data for test problem 1 (fixed temperatures).

\begin{tabular}{ccccccrr}
\hline \multicolumn{2}{l}{ Test problem 1: 6 hot and 6 cold streams } & & & & \\
\hline Hot stream & $\mathrm{FCp}\left(\mathrm{kW} /{ }^{\circ} \mathrm{C}\right)$ & Inlet T $\left({ }^{\circ} \mathrm{C}\right)$ & Outlet $\mathrm{T}\left({ }^{\circ} \mathrm{C}\right)$ & Cold stream & $\mathrm{FCp}\left(\mathrm{kW} /{ }^{\circ} \mathrm{C}\right)$ & Inlet T $\left({ }^{\circ} \mathrm{C}\right)$ & Outlet T $\left({ }^{\circ} \mathrm{C}\right)$ \\
\hline $\mathrm{H} 1$ & 1.00 & 280 & 100 & $\mathrm{C} 1$ & 0.50 & 30 & 200 \\
$\mathrm{H} 2$ & 3.00 & 200 & 80 & $\mathrm{C} 2$ & 1.50 & 60 & 90 \\
$\mathrm{H} 3$ & 1.00 & 220 & 150 & $\mathrm{C} 3$ & 2.00 & 70 & 170 \\
$\mathrm{H} 4$ & 2.00 & 210 & 90 & $\mathrm{C} 4$ & 3.00 & 110 & 230 \\
$\mathrm{H} 5$ & 1.00 & 250 & 180 & $\mathrm{C} 5$ & 1.50 & 90 & 140 \\
$\mathrm{H} 6$ & 2.00 & 270 & 120 & $\mathrm{C} 6$ & 4.00 & 120 & 250 \\
\hline
\end{tabular}

Price of steam: $\$ 80 \mathrm{~kg} / \mathrm{kW}$.

Price of cooling water: $\$ 20 \mathrm{~kg} / \mathrm{kW}$.

To validate the model (see Eq.(17)), our results are compared with the results obtained by the pinch location method, in its disjunctive version, proposed by Grossmann et al. (1998) and the results obtained according to the method proposed by Navarro-Amorós et al. (2013).

The solution of this example is shown in Table 3.

Table 3. Computational statistics and solution of test problem 1 (fixed temperatures).

\begin{tabular}{lccc}
\hline Results test problem 1 & & & \\
\hline & Present work & GYK model & Navarro-Amorós et al. \\
\hline No equations & 890 & 1622 & 6059 \\
No variables & 886 & 614 & 1169 \\
No binary variables & 288 & 432 & 900 \\
& & & \\
CPU time (s) & 0.20 & 0.27 & 0.35 \\
Heating requirements (kW/kg) & 80.00 & 80.00 & 80.00 \\
Cooling requirements (kW/kg) & 15.00 & 15.00 & 15.00 \\
& & & \\
Optimal solution (\$) & 6700.00 & 6700.00 & 6700.00 \\
Solution of relaxed problem & 6700.00 & 5200.00 & 0.00 \\
\hline
\end{tabular}

antel Core i7-4790 3.60GHz, using CPLEX 12.4.6 for MILP.

The results show that the number of continuous and binary variables and total equations is lower in the proposed model versus the other methods, even though the total number of variables is larger than in the original disjunctive PLM. The optimal solution (\$6700) is exactly the same in all cases. Regarding the solution of the relaxed problem, the proposed model obtains the best possible solution.

\subsection{Case study 2: Process with variable stream conditions (MILP)}

In the following examples, inlet and outlet temperatures for hot and cold streams are variables. For these examples, we have assumed that temperature variation does not affect the rest of the process. To validate our model (see Eq.(17)), these test problems are also compared with results obtained by the pinch location method (Grossmann et al., 1998) and the method proposed by Navarro-Amorós et al. (2013).

As in the preceding case, the objective function consists of minimizing the utility cost, remaining the heat flow rates as constant values.

Data for different test problems are shown in Table 4. 
Table 4. Data for test problem 2-5 (variable temperatures).

\begin{tabular}{|c|c|c|c|c|c|c|c|}
\hline Hot stream & $\mathrm{FCp}\left(\mathrm{kW} /{ }^{\circ} \mathrm{C}\right)$ & Inlet $\mathrm{T}\left({ }^{\circ} \mathrm{C}\right)$ & Outlet $\mathrm{T}\left({ }^{\circ} \mathrm{C}\right)$ & Cold stream & $\mathrm{FCp}\left(\mathrm{kW} /{ }^{\circ} \mathrm{C}\right)$ & Inlet $\mathrm{T}\left({ }^{\circ} \mathrm{C}\right)$ & Outlet T $\left({ }^{\circ} \mathrm{C}\right)$ \\
\hline \multicolumn{8}{|c|}{ Test problem 2: 3 hot and 3 cold streams } \\
\hline H1 & 0.15 & $180-260$ & $30-50$ & $\mathrm{C} 1$ & 0.20 & $15-135$ & $170-190$ \\
\hline $\mathrm{H} 2$ & 0.50 & $120-220$ & $75-95$ & $\mathrm{C} 2$ & 0.30 & $110-190$ & $225-235$ \\
\hline $\mathrm{H} 3$ & 0.10 & $110-155$ & $90-100$ & $\mathrm{C} 3$ & 0.15 & $70-130$ & $140-150$ \\
\hline \multicolumn{8}{|c|}{ Test problem 3: 4 hot and 4 cold streams } \\
\hline H1 & 0.15 & $230-260$ & $30-50$ & $\mathrm{C} 1$ & 0.20 & $10-40$ & $170-190$ \\
\hline $\mathrm{H} 2$ & 0.50 & $135-155$ & $110-150$ & $\mathrm{C} 2$ & 0.30 & $90-110$ & $180-225$ \\
\hline H3 & 0.25 & $80-100$ & $20-30$ & C3 & 0.15 & $125-160$ & $225-235$ \\
\hline $\mathrm{H} 4$ & 0.30 & $110-120$ & $80-100$ & $\mathrm{C} 4$ & 0.40 & $130-150$ & $250-280$ \\
\hline
\end{tabular}

Test problem 4: 16 hot and 12 cold streams

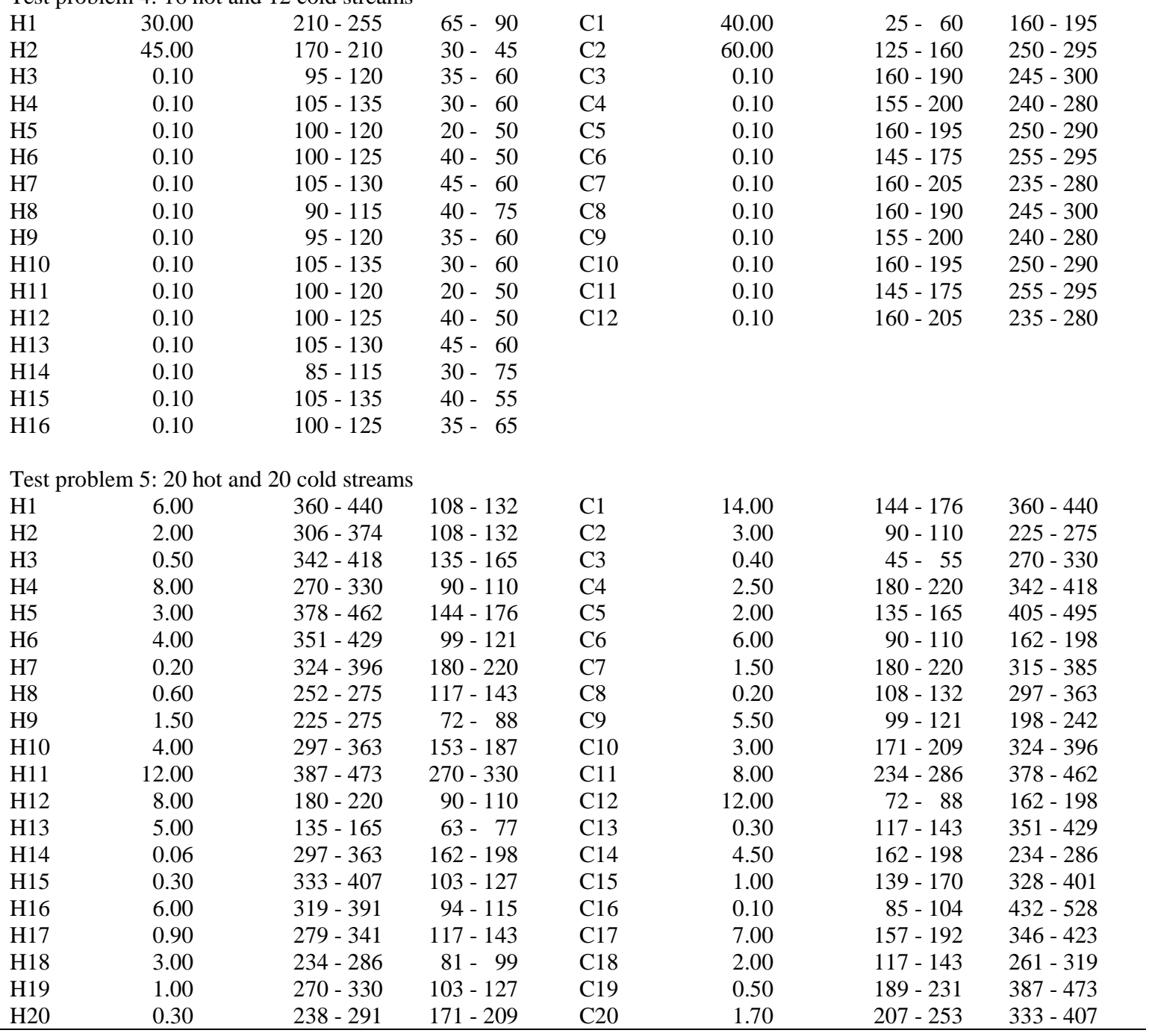

Price of steam: $\$ 80 \mathrm{~kg} / \mathrm{kW}$.

Price of cooling water: $\$ 20 \mathrm{~kg} / \mathrm{kW}$.

In Table 5 and Table 6 we can see the results obtained and some relevant parameters of the test problems. 
Table 5. Results of test problem 2-5 (variable temperatures).

\begin{tabular}{lcccllrl}
\hline Hot stream & $\mathrm{FCp}\left(\mathrm{kW} /{ }^{\circ} \mathrm{C}\right)$ & Inlet $\mathrm{T}\left({ }^{\circ} \mathrm{C}\right)$ & Outlet T $\left({ }^{\circ} \mathrm{C}\right)$ & Cold stream & $\mathrm{FCp}\left(\mathrm{kW} /{ }^{\circ} \mathrm{C}\right)$ & Inlet $\mathrm{T}\left({ }^{\circ} \mathrm{C}\right)$ & Outlet $\mathrm{T}\left({ }^{\circ} \mathrm{C}\right)$ \\
\hline \multicolumn{2}{l}{ Test problem } & $2: 3$ hot and 3 cold streams & & & & & \\
$\mathrm{H} 1$ & 0.15 & 260.00 & 50.00 & $\mathrm{C} 1$ & 0.20 & 15.00 & 190.00 \\
$\mathrm{H} 2$ & 0.50 & 210.00 & 95.00 & $\mathrm{C} 2$ & 0.30 & 110.00 & 225.00 \\
$\mathrm{H} 3$ & 0.10 & 110.00 & 100.00 & $\mathrm{C} 3$ & 0.15 & 70.00 & 150.00
\end{tabular}

Test problem 3: 4 hot and 4 cold streams

\begin{tabular}{|c|c|c|c|c|c|c|c|}
\hline H1 & 0.15 & 260.00 & 50.00 & $\mathrm{C} 1$ & 0.20 & 10.00 & 170.00 \\
\hline $\mathrm{H} 2$ & 0.50 & 155.00 & 120.50 & $\mathrm{C} 2$ & 0.30 & 90.00 & 180.00 \\
\hline H3 & 0.25 & 80.00 & 30.00 & C3 & 0.15 & 160.00 & 225.00 \\
\hline H4 & 0.30 & 110.00 & 100.00 & C4 & 0.40 & 150.00 & 250.00 \\
\hline
\end{tabular}

Test problem 4: 16 hot and 12 cold streams

$\begin{array}{lrrr}\text { H1 } & 30.00 & 255.00 & 90.00 \\ \text { H2 } & 45.00 & 210.00 & 45.00 \\ \text { H3 } & 0.10 & 95.00 & 60.00 \\ \text { H4 } & 0.10 & 105.00 & 60.00 \\ \text { H5 } & 0.10 & 100.00 & 50.00 \\ \text { H6 } & 0.10 & 100.00 & 50.00 \\ \text { H7 } & 0.10 & 105.00 & 60.00 \\ \text { H8 } & 0.10 & 90.00 & 75.00 \\ \text { H9 } & 0.10 & 95.00 & 60.00 \\ \text { H10 } & 0.10 & 105.00 & 60.00 \\ \text { H11 } & 0.10 & 100.00 & 50.00 \\ \text { H12 } & 0.10 & 100.00 & 50.00 \\ \text { H13 } & 0.10 & 105.00 & 60.00 \\ \text { H14 } & 0.10 & 85.00 & 75.00 \\ \text { H15 } & 0.10 & 105.00 & 55.00 \\ \text { H16 } & 0.10 & 100.00 & 65.00\end{array}$

Test problem 5: 20 hot and 20 cold streams

\begin{tabular}{lrrrrrrr} 
H1 & 6.00 & 423.00 & 127.00 & $\mathrm{C} 1$ & 14.00 & 149.00 & 365.00 \\
H2 & 2.00 & 337.00 & 127.00 & $\mathrm{C} 2$ & 3.00 & 95.00 & 270.00 \\
H3 & 0.50 & 337.00 & 149.00 & $\mathrm{C} 3$ & 0.40 & 50.00 & 335.00 \\
H4 & 8.00 & 325.00 & 105.00 & $\mathrm{C} 4$ & 2.50 & 225.00 & 423.00 \\
H5 & 3.00 & 437.00 & 149.00 & $\mathrm{C} 5$ & 2.00 & 140.00 & 437.00 \\
H6 & 4.00 & 365.00 & 116.00 & $\mathrm{C} 6$ & 6.00 & 95.00 & 182.00 \\
H7 & 0.20 & 365.00 & 175.00 & $\mathrm{C} 7$ & 1.50 & 225.00 & 365.00 \\
H8 & 0.60 & 286.00 & 138.00 & $\mathrm{C} 8$ & 0.20 & 113.00 & 365.00 \\
H9 & 1.50 & 270.00 & 83.00 & $\mathrm{C} 9$ & 5.50 & 104.00 & 247.00 \\
H10 & 4.00 & 337.00 & 182.00 & $\mathrm{C} 10$ & 3.00 & 214.00 & 401.00 \\
H11 & 12.00 & 423.00 & 270.00 & $\mathrm{C} 11$ & 8.00 & 286.00 & 383.00 \\
H12 & 8.00 & 182.00 & 105.00 & $\mathrm{C} 12$ & 12.00 & 77.00 & 203.00 \\
H13 & 5.00 & 130.00 & 72.00 & $\mathrm{C} 13$ & 0.30 & 122.00 & 423.00 \\
H14 & 0.06 & 337.00 & 162.00 & $\mathrm{C} 14$ & 4.50 & 167.00 & 291.00 \\
H15 & 0.30 & 401.00 & 122.00 & $\mathrm{C} 15$ & 1.00 & 144.00 & 406.00 \\
H16 & 6.00 & 365.00 & 110.00 & $\mathrm{C} 16$ & 0.10 & 90.00 & 437.00 \\
H17 & 0.90 & 336.00 & 138.00 & $\mathrm{C} 17$ & 7.00 & 162.00 & 365.00 \\
H18 & 3.00 & 236.00 & 94.00 & $\mathrm{C} 18$ & 2.00 & 122.00 & 286.00 \\
H19 & 1.00 & 325.00 & 122.00 & $\mathrm{C} 19$ & 0.50 & 236.00 & 401.00 \\
H20 & 0.30 & 286.00 & 167.00 & $\mathrm{C} 20$ & 1.70 & 236.00 & 338.00 \\
\hline
\end{tabular}

$\begin{array}{lrrr}\text { C1 } & 40.00 & 25.00 & 160.00 \\ \text { C2 } & 60.00 & 136.32 & 250.00 \\ \text { C3 } & 0.10 & 190.00 & 245.00 \\ \text { C4 } & 0.10 & 200.00 & 240.00 \\ \text { C5 } & 0.10 & 195.00 & 250.00 \\ \text { C6 } & 0.10 & 175.00 & 255.00 \\ \text { C7 } & 0.10 & 205.00 & 235.00 \\ \text { C8 } & 0.10 & 190.00 & 245.00 \\ \text { C9 } & 0.10 & 200.00 & 240.00 \\ \text { C10 } & 0.10 & 195.00 & 250.00 \\ \text { C11 } & 0.10 & 175.00 & 255.00 \\ \text { C12 } & 0.10 & 205.00 & 235.00\end{array}$


Table 6. Computational statistics and solution of test problem 2-5 (variable temperatures).

\begin{tabular}{|c|c|c|c|c|c|c|c|c|}
\hline & $\begin{array}{l}\text { No } \\
\text { equations }\end{array}$ & $\begin{array}{l}\text { No } \\
\text { variables }\end{array}$ & $\begin{array}{l}\text { No } \\
\text { binary } \\
\text { variables }\end{array}$ & $\begin{array}{l}\mathrm{CPU} \\
\text { time }(\mathrm{s})^{\mathrm{a}}\end{array}$ & $\begin{array}{l}\text { Heating } \\
\text { requirements } \\
(\mathrm{kW} / \mathrm{kg})\end{array}$ & $\begin{array}{l}\text { Cooling } \\
\text { requirements } \\
(\mathrm{kW} / \mathrm{kg})\end{array}$ & $\begin{array}{l}\text { Optimal } \\
\text { solution } \\
\text { (\$) }\end{array}$ & $\begin{array}{l}\text { Solution } \\
\text { of relaxed } \\
\text { problem }\end{array}$ \\
\hline \multicolumn{9}{|c|}{ Test problem 2} \\
\hline $\begin{array}{l}\text { Present } \\
\text { work }\end{array}$ & 230 & 237 & 42 & 0.03 & 0.0 & 8.5 & 170.0 & 0.00 \\
\hline $\begin{array}{l}\text { GYK } \\
\text { model }\end{array}$ & 416 & 171 & 108 & 0.45 & 0.0 & 8.5 & 170.0 & 0.00 \\
\hline $\begin{array}{l}\text { Navarro- } \\
\text { Amorós }\end{array}$ & 3047 & 1247 & 216 & 0.75 & 0.0 & 8.5 & 170.0 & 0.00 \\
\hline \multicolumn{9}{|c|}{ Test problem 3} \\
\hline $\begin{array}{l}\text { Present } \\
\text { work }\end{array}$ & 402 & 411 & 26 & 0.02 & 49.5 & 5.0 & 4060.0 & 3282.73 \\
\hline $\begin{array}{l}\text { GYK } \\
\text { model }\end{array}$ & 730 & 291 & 192 & 0.11 & 49.5 & 5.0 & 4060.0 & 620.00 \\
\hline $\begin{array}{l}\text { Navarro- } \\
\text { Amorós }\end{array}$ & 5375 & 2125 & 307 & 0.22 & 49.5 & 5.0 & 4060.0 & 3124.02 \\
\hline \multicolumn{9}{|c|}{ Test problem 4} \\
\hline $\begin{array}{l}\text { Present } \\
\text { work }\end{array}$ & 4762 & 4791 & 364 & 0.14 & 1694.0 & 1852.2 & 172564.0 & 84768.34 \\
\hline $\begin{array}{l}\text { GYK } \\
\text { model }\end{array}$ & 8710 & 3251 & 2352 & 0.42 & 1694.0 & 1852.2 & 172564.0 & 0.00 \\
\hline $\begin{array}{l}\text { Navarro- } \\
\text { Amorós }\end{array}$ & 44719 & 5857 & 4763 & 1000.05 & 1694.0 & 1852.2 & 172564.0 & 0.00 \\
\hline \multicolumn{9}{|c|}{ Test problem 5} \\
\hline $\begin{array}{l}\text { Present } \\
\text { work }\end{array}$ & 9682 & 9723 & 704 & 0.36 & 0.0 & 116.3 & 2326.0 & 0.00 \\
\hline $\begin{array}{l}\text { GYK } \\
\text { model }\end{array}$ & 17722 & 6563 & 4800 & 37.74 & 0.0 & 116.3 & 2326.0 & 0.00 \\
\hline $\begin{array}{l}\text { Navarro- } \\
\text { Amorós }\end{array}$ & 109799 & 11725 & 9683 & 1161.33 & 0.0 & 116.3 & 2326.0 & 0.00 \\
\hline
\end{tabular}

260 As it is shown in Table 6, for test problem 2, the optimal solution is $\$ 170$ for all cases, and the relaxation gap for 261 all methods is bad because the solution to the relaxed problem is equal to zero.

262 The optimal solution to test problem 3 is $\$ 4060$ and the relaxation gap of the proposed model is much better than 263 the relaxation gap obtained by the other methods (19\% in the novel model, $84 \%$ in the Grossmann Disjunctive 264 model and $23 \%$ in the model by Navarro-Amorós et al. (2013)).

265 The same behavior occurs on test problem 4. The optimal solution to test problem 4 is $\$ 172564$ and the 266 relaxation gap is better than the gap obtained by the others models. It is the only model with relaxation different 267 from zero.

268 Regarding the test problem 5, the optimal solution and the relaxation gap is the same for all cases. However, it is 269 interesting to remark the CPU time difference between the models. Indubitably, our model is much faster than 270 the other methods, allowing to solve problems with a high number of hot and cold streams.

\subsection{Case study 3: Process with variable stream conditions with penalty function (MINLP)}

In previous examples, we assumed that the operating conditions do not affect the heat integration and, therefore, basically the optimal solution select the temperatures that allow the maximum heat integration. In order to simulate the behavior of an actual system, we propose an example in which the temperatures for the optimal operating conditions without heat integration are known and any deviation of those values carries out a penalty in the total cost. 
In this case study (test problem 6), the objective function consists of two parts; the first one concerns the cost of utilities, and the second term penalizes the deviation of temperature from a given set value:

$$
\min \left(\operatorname{cost}_{H} Q_{H}+\cos _{C} Q_{C}\right)+w \cdot \sum_{k \in S T}\left(T_{k}^{\text {in }}-T M_{k}^{\text {in }}\right)^{2}+\left(T_{k}^{\text {out }}-T M_{k}^{\text {out }}\right)^{2}
$$

where $w$ is the penalization factor and TM are the optimal temperatures of the non-heat integrated process (we have assumed that the optimal temperatures are the mean values between the upper and lower bounds).

Data used in this case are shown in Table 7.

Table 7. Data for test problem 6 (non-linear, variable temperatures).

\begin{tabular}{llllllll}
\hline \multicolumn{2}{l}{ Test problem 6 (non-linear): 3 hot and 3 cold streams } \\
\hline Hot stream & $\mathrm{FCp}\left(\mathrm{kW} /{ }^{\circ} \mathrm{C}\right)$ & Inlet $\mathrm{T}\left({ }^{\circ} \mathrm{C}\right)$ & Outlet T $\left({ }^{\circ} \mathrm{C}\right)$ & Cold stream & $\mathrm{FCp}\left(\mathrm{kW} /{ }^{\circ} \mathrm{C}\right)$ & Inlet T $\left({ }^{\circ} \mathrm{C}\right)$ & Outlet $\mathrm{T}\left({ }^{\circ} \mathrm{C}\right)$ \\
\hline $\mathrm{H} 1$ & 0.15 & $180-260$ & $30-50$ & $\mathrm{C} 1$ & 0.20 & $15-25$ & $170-190$ \\
$\mathrm{H} 2$ & 0.50 & $120-140$ & $75-95$ & $\mathrm{C} 2$ & 0.30 & $110-140$ & $225-235$ \\
$\mathrm{H} 3$ & 0.10 & $110-155$ & $90-100$ & $\mathrm{C} 3$ & 0.15 & $70-100$ & $140-150$ \\
\hline
\end{tabular}

Price of steam: $\$ 80 \mathrm{~kg} / \mathrm{kW}$.

Price of cooling water: $\$ 20 \mathrm{~kg} / \mathrm{kW}$.

In this case, the model is a non-convex MINLP problem. The optimal solution achieved with our model (\$2900.5) is better than the solution obtained by the other models (the same initial point was used in all the cases). Furthermore, the relaxation gap is considerably reduced compared to the other models. For this case, the results and the other relevant parameters are shown in Table 8 and Table 9, respectively.

Table 8. Results of test problem 6 (non-lineal, variable temperatures).

\begin{tabular}{llllllll}
\hline \multicolumn{2}{l}{ Test problem 6 (non-linear): 3 hot and 3 cold streams } \\
\hline Hot stream & FCp $\left(\mathrm{kW} /{ }^{\circ} \mathrm{C}\right)$ & Inlet $\mathrm{T}\left({ }^{\circ} \mathrm{C}\right)$ & Outlet $\mathrm{T}\left({ }^{\circ} \mathrm{C}\right)$ & Cold stream & $\mathrm{FCp}\left(\mathrm{kW} /{ }^{\circ} \mathrm{C}\right)$ & Inlet T $\left({ }^{\circ} \mathrm{C}\right)$ & Outlet $\mathrm{T}\left({ }^{\circ} \mathrm{C}\right)$ \\
\hline $\mathrm{H} 1$ & 0.15 & 260.00 & 50.00 & $\mathrm{C} 1$ & 0.20 & 15.00 & 190.00 \\
$\mathrm{H} 2$ & 0.50 & 210.00 & 95.00 & $\mathrm{C} 2$ & 0.30 & 110.00 & 225.00 \\
$\mathrm{H} 3$ & 0.10 & 110.00 & 100.00 & $\mathrm{C} 3$ & 0.15 & 70.00 & 150.00 \\
\hline
\end{tabular}

Table 9. Computational statistics and solution of test problem 5 (non-linear, variable temperatures).

\begin{tabular}{lccc}
\hline Test problem 6 & & & \\
\hline & Present work & GYK model & Navarro-Amorós et al. \\
\hline No equations & 230 & 416 & 3047 \\
No variables & 237 & 171 & 1247 \\
No binary variables & 17 & 108 & 216 \\
& & & \\
CPU time (s) & & 0.68 & 3.33 \\
Heating requirements (kW/kg) & 29.25 & 28.90 & 29.25 \\
Cooling requirements (kW/kg) & 10.80 & 12.76 & 11.11 \\
& & & \\
Optimal solution (\$) & 2900.50 & 2918.63 & 2903.63 \\
Solution of relaxed problem & 2002.62 & 767.00 & 1904.73 \\
\hline
\end{tabular}

antel Core i7-4790 3.60GHz, using DICOPT for MINLP.

Optimization has been performed with different weights of the penalization factor $w$ (see Eq. (23)). The optimal results are shown in Fig. 2.

<Insert Fig. 2> 
The results show that when the penalty factor is lower than two, the optimal solution is mainly affected by the utility costs. However, when the penalty factor increases, the term that penalizes the deviation of temperature from the central values between the upper and lower bounds is the most important factor, making the optimal solution constant (around \$3300).

\subsection{Case study 4: Hybrid simulation-optimization process (MINLP)}

Another case study performed was a hybrid simulation-optimization problem, in which the heat integration in the form of explicit equations is combined with the simulation of a chemical process. The process was simulated in Aspen HYSYS v.8.4. (Hyprotech, 1995 - 2011). As MINLP solver, we use an in-house implementation (Caballero et al., 2014) of a basic Branch and Bound algorithm interfaced with TOMLAB-MATLAB (Holmström, 1999).

The following case study corresponds to the design of a natural gas plant (Seider et al., 1999). Consider that we want to obtain a gaseous product with at least $4500 \mathrm{kmol} / \mathrm{h}$ of $\mathrm{nC}_{4}$ and lighter species, with a combined mole percentage of at least $99.5 \%$ and at $2026 \mathrm{kPa}$. The liquid product is required to be at least $1034 \mathrm{kPa}$, with at least $30 \mathrm{kmol} / \mathrm{h}$ of $\mathrm{nC}_{5}$ and $\mathrm{nC}_{6}$ and a combined mole percentage of at least $65 \%$. Data for the problem are shown in Table 10 .

Table 10. Feed data to natural gas flowsheet.

\begin{tabular}{lrl}
\hline \multicolumn{3}{c}{ Feed stream } \\
\hline Molar flow & 5000.0 & $\mathrm{kmol} / \mathrm{h}$ \\
Composition (molar flows) & 4138.0 & $\mathrm{kmol} / \mathrm{h}$ \\
$\mathrm{C}_{1}$ & 435.5 & $\mathrm{kmol} / \mathrm{h}$ \\
$\mathrm{C}_{2}$ & 205.5 & $\mathrm{kmol} / \mathrm{h}$ \\
$\mathrm{C}_{3}$ & 70.5 & $\mathrm{kmol} / \mathrm{h}$ \\
$\mathrm{nC}_{4}$ & 28.5 & $\mathrm{kmol} / \mathrm{h}$ \\
$\mathrm{nC}_{5}$ & 16.5 & $\mathrm{kmol} / \mathrm{h}$ \\
$\mathrm{nC}_{6}$ & 105.5 & $\mathrm{kmol} / \mathrm{h}$ \\
$\mathrm{N}_{2}$ & 20.0 & ${ }^{\circ} \mathrm{C}$ \\
Temperature & 1013.0 & $\mathrm{kPa}$ \\
Pressure & Peng-Robinson \\
Thermodynamics (fluid package) & \multicolumn{2}{c}{}
\end{tabular}

The flowsheet for the process is shown in Fig. 3. The feed is compressed to $2280 \mathrm{kPa}$, and is cooled before entering the flash unit, at $2103 \mathrm{kPa}$. The flash products are heated. The liquid product enters in the second flash vessel, at $2068 \mathrm{kPa}$. Its liquid product is fed to the distillation column, where most of the propane is removed by overhead. The column has 12 theoretical trays, and the feed enters to the fourth tray from the top. The column recovers $99 \%$ of $\mathrm{C}_{3}$ in the distillate and $99 \%$ of $\mathrm{nC}_{5}$ in the bottoms.

\section{<Insert Fig. 3>}

Fig. 3. Process flow diagram for natural gas synthesis.

We assume that the cost of the process are not considerably affected (the TAC of the system is around \$3.039 million/year, without the heat and cooling requirements). As a result, it is not taken into account, but changes in temperatures modified the operating conditions and the purity constraints must be met. Therefore, the objective of this problem consists of minimizing the heat supplied by the hot and the cold utilities. The streams affected by the heat integration were all inlet and outlet streams of the heat exchangers, and the streams of the condenser (the reboiler was not taken into account because, by the temperature differences, it cannot be heat integrated). The temperature bounds for all streams, the main constraints, and the optimal solution are shown in Table 11. 
Table 11. Data and optimal solution to natural gas flowsheet.

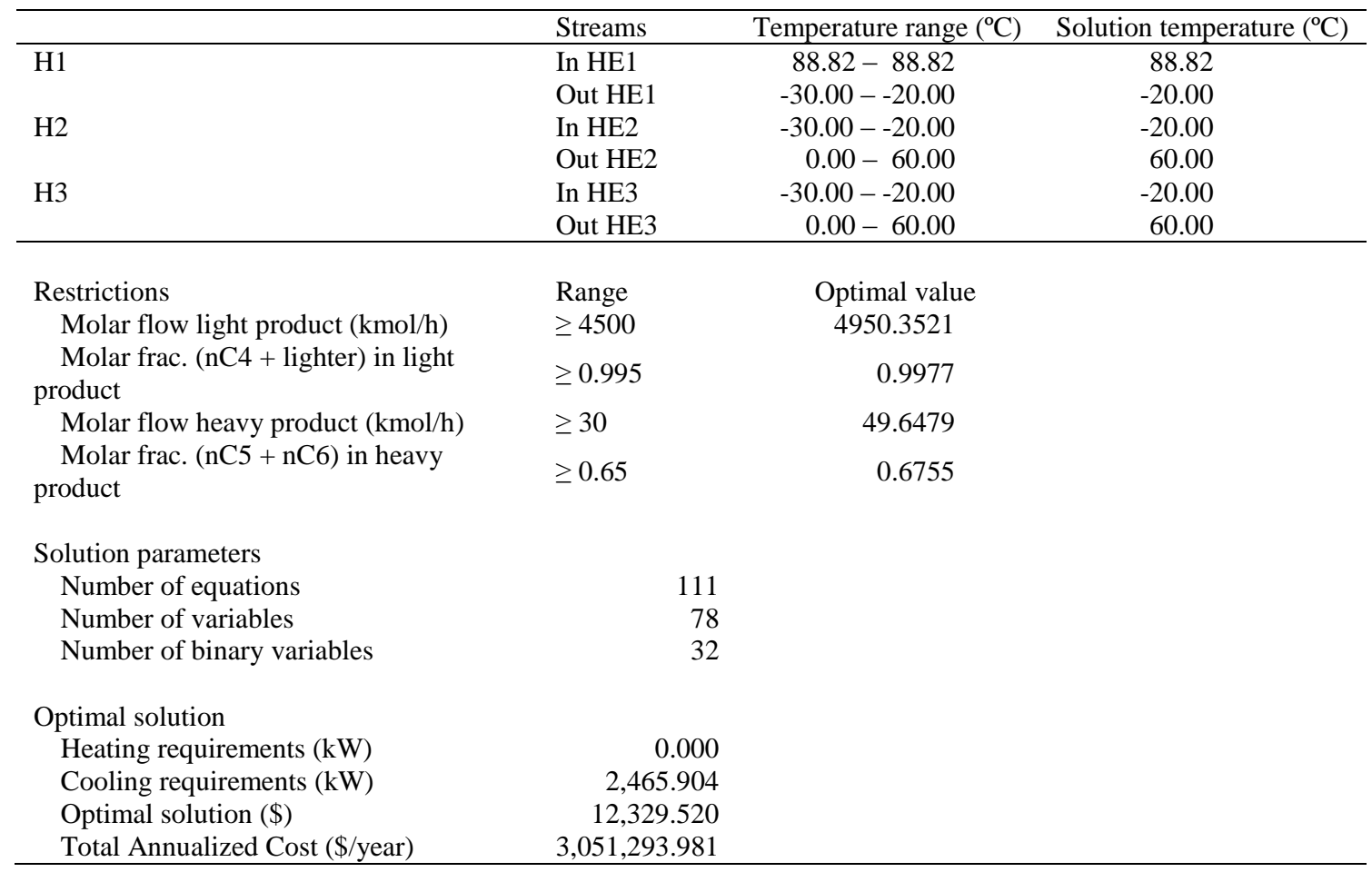

Table 11 shows that the optimal solution satisfies all the constraints. Furthermore, the heat integration of the system eliminates the need for hot utility (except the hot utility needed in the reboiler, which does not affect the heat exchanger network); only cold utilities are needed to satisfy the requirements of the process. The heat exchanger network is shown in Fig. 4.

Fig. 4. Heat exchanger network for natural gas process.

This case study shows that the proposed model can be implemented to optimize hybrid simulation-optimization problems, in which the process simulation is combined with the heat integration in the form of explicit equations.

\subsection{Case study 5: Extension of the method to multiple utilities (MILP)}

As a final point, the method has been extended to the case of multiple utilities. In the next examples, all inlet and outlet streams are variables.

The first example (test problem 7) corresponds to a problem with four hot streams and six cold streams. We have considered the possibility of adding a new hot utility $\left(T H_{M P}=254^{\circ} \mathrm{C}\right.$, ). The objective function consists of minimizing the utility costs $\left(C_{H P} Q_{H P}+C_{M P} Q_{M P}+C_{C} Q_{C}\right)$.

The second example (test problem 8) corresponds to a problem with two hot streams and one cold stream. We have consider the possibility of adding two new hot utilities, $\left(T H_{M P}=160^{\circ} \mathrm{C}\right)$ and $\left(T H_{L P}=130^{\circ} \mathrm{C}\right)$. The objective function consists of minimizing the utility costs $\left(C_{H P} Q_{H P}+C_{M P} Q_{M P}+C_{L P} Q_{L P}+C_{C} Q_{C}\right)$.

Data used in this case study are shown in Table 12. 
Table 12. Data for case study 5 (non-linear, variable temperatures).

\begin{tabular}{|c|c|c|c|c|c|c|c|}
\hline Hot stream & $\mathrm{FCp}\left(\mathrm{kW} /{ }^{\circ} \mathrm{C}\right)$ & Inlet $\mathrm{T}\left({ }^{\circ} \mathrm{C}\right)$ & Outlet $\mathrm{T}\left({ }^{\circ} \mathrm{C}\right)$ & Cold stream & $\mathrm{FCp}\left(\mathrm{kW} /{ }^{\circ} \mathrm{C}\right)$ & Inlet $\mathrm{T}\left({ }^{\circ} \mathrm{C}\right)$ & Outlet $\mathrm{T}\left({ }^{\circ} \mathrm{C}\right)$ \\
\hline \multicolumn{8}{|c|}{ Test problem 7: 4 hot and 6 cold streams } \\
\hline H1 & 0.100 & $315-327$ & $20-30$ & $\mathrm{C} 1$ & 0.200 & $85-110$ & $290-330$ \\
\hline $\mathrm{H} 2$ & 0.250 & $210-220$ & $140-160$ & $\mathrm{C} 2$ & 0.070 & $25-55$ & $160-185$ \\
\hline H3 & 0.020 & $200-220$ & $50-60$ & $\mathrm{C} 3$ & 0.175 & $70-95$ & $120-140$ \\
\hline \multirow[t]{3}{*}{$\mathrm{H} 4$} & 0.340 & $155-160$ & $40-45$ & $\mathrm{C} 4$ & 0.060 & $55-70$ & $150-185$ \\
\hline & & & & C5 & 0.200 & $135-150$ & $270-320$ \\
\hline & & & & C6 & 0.300 & $8-30$ & $42-75$ \\
\hline \multicolumn{8}{|c|}{ Test problem 8: 2 hot and 1 cold stream } \\
\hline $\mathrm{H} 1$ & 10.000 & $95-115$ & $15-35$ & $\mathrm{C} 1$ & 7.500 & $15-35$ & $175-195$ \\
\hline $\mathrm{H} 2$ & 5.000 & $175-195$ & $25-45$ & & & & \\
\hline
\end{tabular}

Price of HP steam: $\$ 160 \mathrm{~kg} / \mathrm{kW}$.

Price of MP steam: $\$ 110 \mathrm{~kg} / \mathrm{kW}$.

Price of LP steam: $\$ 50 \mathrm{~kg} / \mathrm{kW}$.

Price of cooling water: $\$ 10 \mathrm{~kg} / \mathrm{kW}$.

Results have been compared with the same process, but taking into account only single utilities, where the objective function consist of minimizing the utility costs $\left(C_{H} Q_{H}+C_{C} Q_{C}\right)$.

For test problem 7, the optimal solution achieved is $\$ 2533.0$, while the optimal solution obtained taking into account only single utilities is \$3168.0. Regarding the solution obtained for test problem 8, the optimal solution achieved adding two utilities is $\$ 16875$, while the optimal solution obtained taking into account only one hot utility is $\$ 24750.0$.

The results obtained and other relevant parameters of case study 5 are shown in Table 13 and Table 14, 366 respectively.

Table 13. Computational statistics and solution of test problem 7 (variable temperatures).

\begin{tabular}{lcc}
\hline & $\begin{array}{r}\text { Test problem 7 } \\
\text { (single utilities) }\end{array}$ & $\begin{array}{c}\text { Test problem 7 } \\
\text { (multiple utilities) }\end{array}$ \\
\hline No equations & 622 & 749 \\
No variables & 633 & 547 \\
No binary variables & 29 & 29 \\
$\quad$ & \\
CPU time (s) & 0.11 & 0.86 \\
Heating requirements (kW/kg) & & 7.10 \\
$\quad$ HP steam & 19.80 & 12.70 \\
$\quad$ MP steam & - & 0.0 \\
Cooling requirements (kW/kg) & 0.00 & \\
$\quad$ & & 2533.00 \\
$\quad$ Optimal solution (\$) & 3168.00 & 2357.00 \\
Solution of relaxed problem & 2912.00 & \\
\hline
\end{tabular}


Table 14. Computational statistics and solution of test problem 8 (variable temperatures).

\begin{tabular}{|c|c|c|}
\hline & $\begin{array}{c}\text { Test problem } 8 \\
\text { (single utilities) }\end{array}$ & $\begin{array}{c}\text { Test problem } 8 \\
\text { (multiple utilities) }\end{array}$ \\
\hline No equations & 62 & 160 \\
\hline No variables & 66 & 120 \\
\hline No binary variables & 6 & 6 \\
\hline CPU time $(\mathrm{s})^{\mathrm{a}}$ & 0.08 & 0.52 \\
\hline \multicolumn{3}{|l|}{ Heating requirements $(\mathrm{kW} / \mathrm{kg})$} \\
\hline HP steam & 125.00 & 12.50 \\
\hline MP steam & - & 75.00 \\
\hline LP steam & - & 37.50 \\
\hline Cooling requirements $(\mathrm{kW} / \mathrm{kg})$ & 475.00 & 475.00 \\
\hline Optimal solution (\$) & 24750.00 & 16875.00 \\
\hline Solution of relaxed problem & 7750.00 & 16375.00 \\
\hline
\end{tabular}

${ }^{\mathrm{a}}$ Intel Core i7-4790 3.60GHz, using CPLEX 12.4.6 for MILP.

In addition, as it is shown in Table 13 and Table 14, the relaxation gap is reasonable.

\section{Conclusions}

We have proposed a new MILP model based on disjunctive programming for the simultaneous optimization and energy integration of systems with variable input and output process stream temperatures. This model allows us to obtain a robust alternative to the disjunctive model for the simultaneous flowsheet optimization and heat integration proposed by Grossmann et al. (1998).

The results show that our model is very competitive from the point of view of CPU time, includes fewer binary variables and equations, although the number of total variables is slightly larger than the original disjunctive formulation. Furthermore, the proposed model improves the relaxation gap, compared to two different methods.

Different test problems have shown that the model is robust and reliable. One of the main characteristics of the novel model is that it can be 'added' to any model with almost no modifications of the existing model and, therefore, its implementation is straightforward. If the heat flows in the original model are not affected by the temperature then the new equations are all linear, with some integer variables, and therefore we do not expect a significant increase in the complexity of the original model.

\section{Acknowledgments}

The authors gratefully acknowledge the financial support by the Ministry of Economy and Competitiveness from Spain, under the project CTQ2012-37039-C02-02, and Call 2013 National Sub-Program for Training, Grants for pre-doctoral contracts for doctoral training (BES-2013-064791).

\section{Nomenclature}

$C_{C} \quad$ Cost of the cold utility

$C_{H} \quad$ Cost of the heat utility

$F_{i} \quad$ Heat capacity flowrate of hot stream $i$

$f_{j} \quad$ Heat capacity flowrate of cold stream $j$

$i \quad$ Hot stream

$j \quad$ Cold stream

$m \quad$ Mass flow rate of a stream

$n_{c} \quad$ Number of cold streams 
$n_{h} \quad$ Number of hot streams

$P \quad$ Index set of all the hot and cold process streams (pinch candidates)

$Q_{C} \quad$ Heat removed by the cold utility

$Q_{H} \quad$ Heat provided by the hot utility

$Q_{C}^{p} \quad$ Cooling utilities required form each pinch candidate

$Q_{H}^{p} \quad$ Heating utilities required form each pinch candidate

$Q A_{C}^{p} \quad$ Total cool content above the pinch

$Q A_{H}^{p} \quad$ Total heat content above the pinch

$T^{p} \quad$ Pinch point temperature

$T_{i}^{i n} \quad$ Inlet temperature for the hot stream $i$

$T_{i}^{\text {out }} \quad$ Outlet temperature for the hot stream $i$

$t_{j}^{\text {in }} \quad$ Inlet temperature for the cold stream $j$

$t_{j}^{\text {out }} \quad$ Outlet temperature for the cold stream $j$

$\operatorname{Tin}_{i} \quad$ Actual inlet temperature for the hot stream $i$

$\operatorname{tin}_{j} \quad$ Actual inlet temperature for the cold stream $j$

Tout $_{i} \quad$ Actual outlet temperature for the hot stream $i$

tout $_{j} \quad$ Actual inlet temperature for the cold stream $j$

TM Optimal temperatures of the non-heat integrated process

w Penalization factor

$Y^{i s o} \quad$ Boolean variable that takes the "True" value if the temperature of the isothermal stream is greater than the pinch candidate temperature

$y c \quad$ Binary variable related to the max operator that represents the cold streams

$y h \quad$ Binary variable related to the max operator that represents the hot streams

$\Delta T_{\min } \quad$ Minimum heat recovery approach temperature

$\lambda \quad$ Specific heat associated with the charge of phase

$\Omega \quad$ Total heat surplus

\section{References}

Ahmad S, Linnhoff B, Smith R. Cost optimum heat exchanger networks - 2. targets and design for detailed capital cost models. Comput Chem Eng 1990; 14:751-767.

Ahmetović E, Ibrić N, Kravanja Z, Grossmann IE. Water and energy integration: A comprehensive literature review of non-isothermal water network synthesis. Comput Chem Eng 2015; 82:144-171.

Ahmetović E, Kravanja Z. Simultaneous synthesis of process water and heat exchanger networks. Energy 2013; 57:236-250.

Balakrishna S, Biegler LT. Targeting strategies for the synthesis and energy integration of nonisothermal reactor networks. Ind Eng Chem Prod DD 1992; 31:2152.

Biegler LT. Nonlinear Programming. Concepts, Algorithms, and Applications to Chemical Processes. SIAM. Society for Industrial and Applied Mathematics; 2010.

Caballero JA, Grossmann IE. Structural considerations and modeling in the synthesis of heatintegrated-thermally coupled distillation sequences. Ind Eng Chem Res 2006; 45:8454-8474.

Caballero JA, Navarro MA, Ruiz-Femenia R, Grossmann IE. Integration of different models in the design of chemical processes: Application to the design of a power plant. Appl Energy 2014; 124:256-273.

Corbetta M, Grossmann IE, Manenti F. Process simulator-based optimization of biorefinery downstream processes under the Generalized Disjunctive Programming framework. Comput Chem Eng 2016; 88:73-85.

Dunn RF, El-Halwagi MM. Process integration technology review: background and applications in the chemical process industry. J Chem Technol Biotechnol 2003; 78:1011-1021. 
Duran MA, Grossmann IE. Simultaneous optimization and heat integration of chemical processes. AIChE J 1986; 32:123-138.

Fernández I, Renedo CJ, Pérez SF, Ortiz A, Mañana M. A review: Energy recovery in batch processes. Renew Sust Energ Rev 2012; 16:2260-2277.

Furman KC, Sahinidis NV. A critical review and annotated bibliography for heat exchanger network synthesis in the 20th Century. Ind Eng Chem Res 2002; 41:2335-2370.

Grossmann IE, Caballero JA, Yeomans H. Mathematical programming approaches to the synthesis of chemical process systems. Korean J Chem Eng 1999; 16:407-426.

Grossmann IE, Trespalacios F. Systematic modeling of discrete-continuous optimization models through generalized disjunctive programming. AIChE J 2013; 59:3276-3295.

Grossmann IE, Yeomans $\mathrm{H}$, Kravanja Z. A rigorous disjunctive optimization model for simultaneous flowsheet optimization and heat integration. Comput Chem Eng 1998; 22:A157-A164.

Gundersen T, Naess L. The synthesis of cost optimal heat exchanger networks. Comput Chem Eng 1988; 12:503-530.

Holmström K. The TOMLAB optimization environment in Matlab. Adv Model Optim 1999; 1:47-69.

Hyprotech, Ltd. HYSYS. Hyprotech Ltd. 1995 - 2011.

Jezowski J. Exchanger Network Grassroot and Retrofit Design. The Review of the State-of-the-Art: Part II. Heat Exchanger Network Synthesis by Mathematical Methods and Approaches for Retrofit Design. Hung J Ind Chem 1994a; 22:295-308.

Jezowski J. Heat Exchanger Network Grassroot and Retrofit Design. The Review of the State-of-theArt: Part I. Heat Exchanger Network Targeting and Insight Based Methods of Synthesis. Hung $\mathrm{J}$ Ind Chem 1994b; 22:279-294.

Klemeš JJ, Kravanja Z. Forty years of Heat Integration: Pinch Analysis (PA) and Mathematical Programming (MP). Curr Opin Chem Eng 2013; 2:461-474.

Lang YD, Biegler LT, Grossmann IE. Simultaneous optimization and heat integration with process simulators. Comput Chem Eng 1988; 12:311-327.

Linhoff B, Hindmarsh E. The pinch design method for heat exchange network. Chem Eng Sci 1983; 38:745-763.

Linnhoff B. Pinch analysis - a state-of-the-art overview. Chem Eng Res Des 1993; 71:503-522.

Linnhoff B, Ahmad S. Cost optimum heat exchanger networks-1. Minimum energy and capital using simple models for capital cost. Comput Chem Eng 1990; 14:729-750.

Linnhoff B, Flower JR. Synthesis of heat exchanger networks: I. Systematic generation of energy optimal networks. AIChE J 1978; 24:633-642.

Morar M, Agachi PS. Review: Important contributions in development and improvement of the heat integration techniques. Comput Chem Eng 2010; 34:1171-1179.

Navarro-Amorós MA, Caballero JA, Ruiz-Femenia R, Grossmann IE. An alternative disjunctive optimization model for heat integration with variable temperatures. Comput Chem Eng 2013; 56:12-26.

Onishi VC, Ravagnani MASS, Caballero JA. Simultaneous synthesis of heat exchanger networks with pressure recovery: Optimal integration between heat and work. AIChE J 2014a; 60:893-908.

Onishi VC, Ravagnani MASS, Caballero JA. Simultaneous synthesis of work exchange networks with heat integration. Chem Eng Sci 2014b; 112:87-107.

Papoulias SA, Grossmann IE. A structural optimization approach in process synthesis. Part II: Heat recovery networks. Comput Chem Eng 1983; 7:707-721.

Quirante N, Caballero JA. Large scale optimization of a sour water stripping plant using surrogate models. Comput Chem Eng 2016; 92:143-162.

Rosenthal RE. GAMS - A user's guide. Washington, DC: GAMS Development Corporation; 2012. SCOPUS Database. Scopus Database. 2016.

Seider WD, Seader JD, Lewin DR. Process Design Principles: Synthesis, Analysis, and Evaluation. Wiley; 1999.

Sreepathi BK, Rangaiah GP. Review of heat exchanger network retrofitting methodologies and their applications. Ind Eng Chem Res 2014; 53:11205-11220. 
Wechsung A, Aspelund A, Gundepsen T, Barton PI. Synthesis of Heat Exchanger Networks at Subambient Conditions with Compression and Expansion of Process Streams. AIChE J 2011; 57:2090-2108.

Yee TF, Grossmann IE. Simulatneous optimization models for heat integration II. Heat exchanger network synthesis. Comput Chem Eng 1990; 14:1165-1184.

Yee TF, Grossmann IE, Kravanja Z. Simultaneous optimization models for heat integration III. Process and heat exchanger network optimization. Comput Chem Eng 1990; 14:1185-1200. 


\section{Figure captions}

Fig. 1. Utilities needed for different pinch stream candidates (— Hot - - - Cold). (a) Pinch candidate H1. (b) Pinch candidate H2. (c) Pinch candidate C1. (d) Pinch candidate C2.

Fig. 2. Optimal solutions to test problem 6 for different penalization factors.

Fig. 3. Process flow diagram for natural gas synthesis.

Fig. 4. Heat exchanger network for natural gas process. 


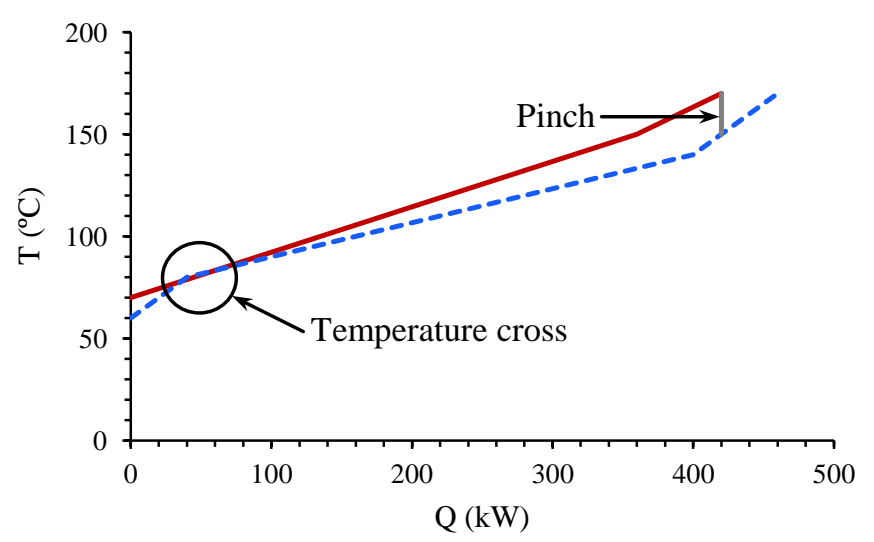

(a)

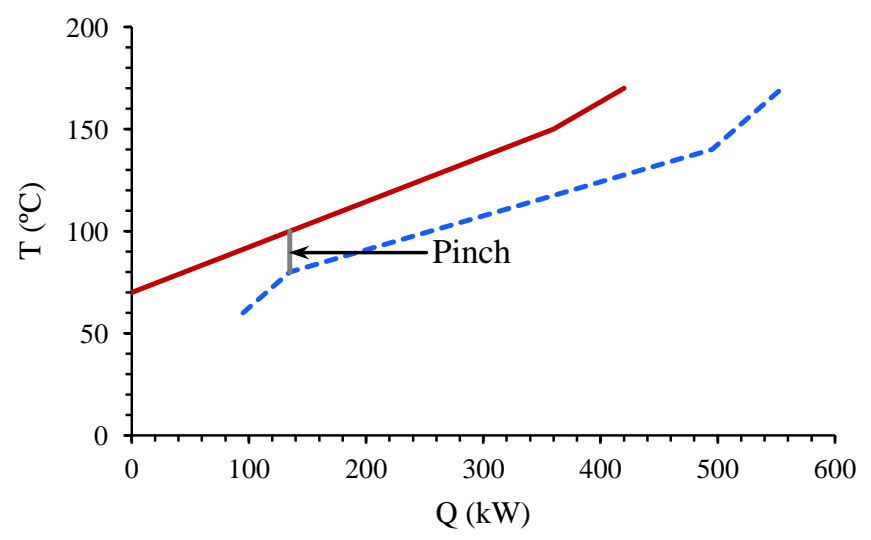

(c)

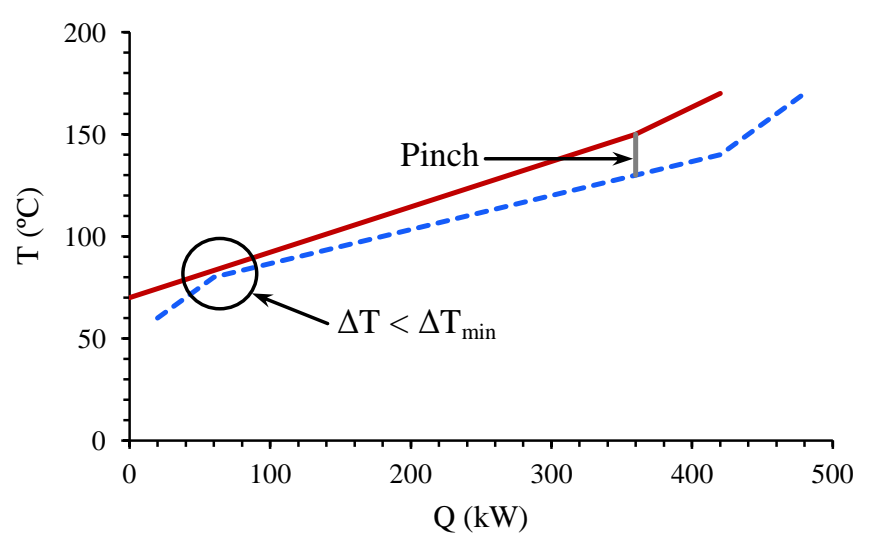

(b)

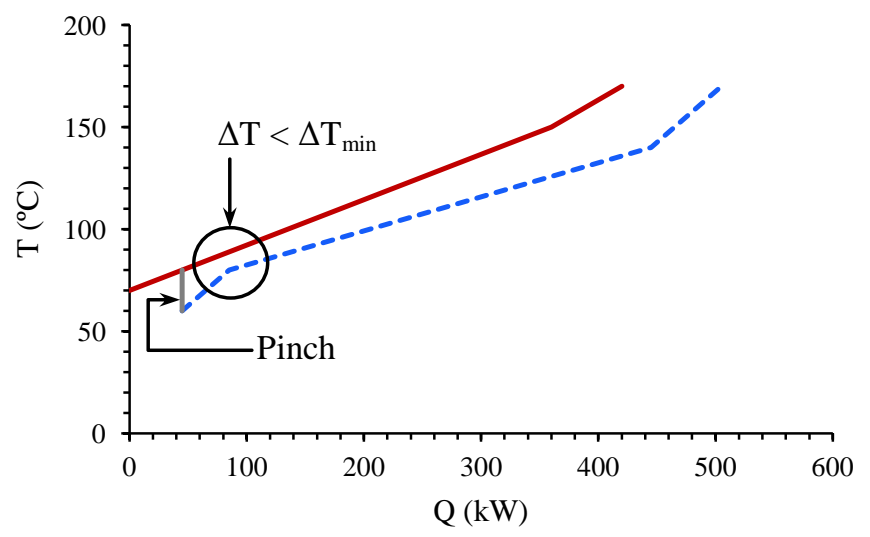

(d) 
Figure(s)

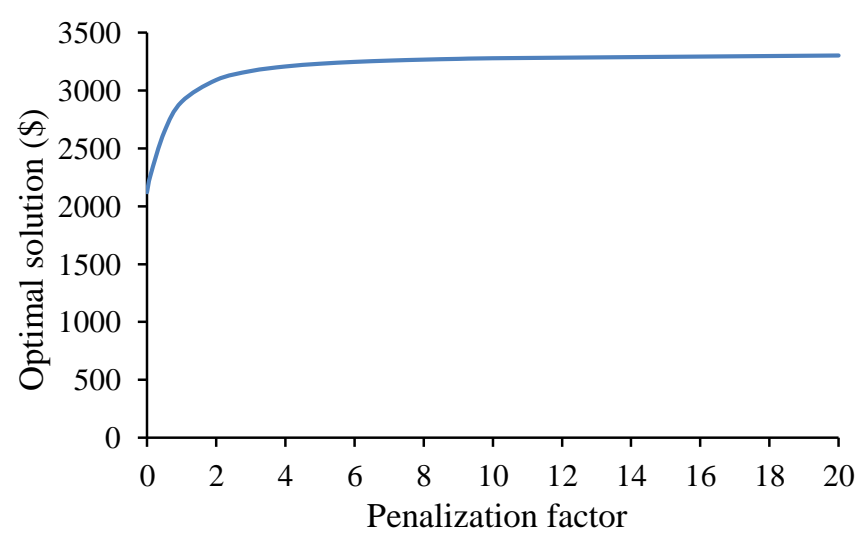

Penalization factor 


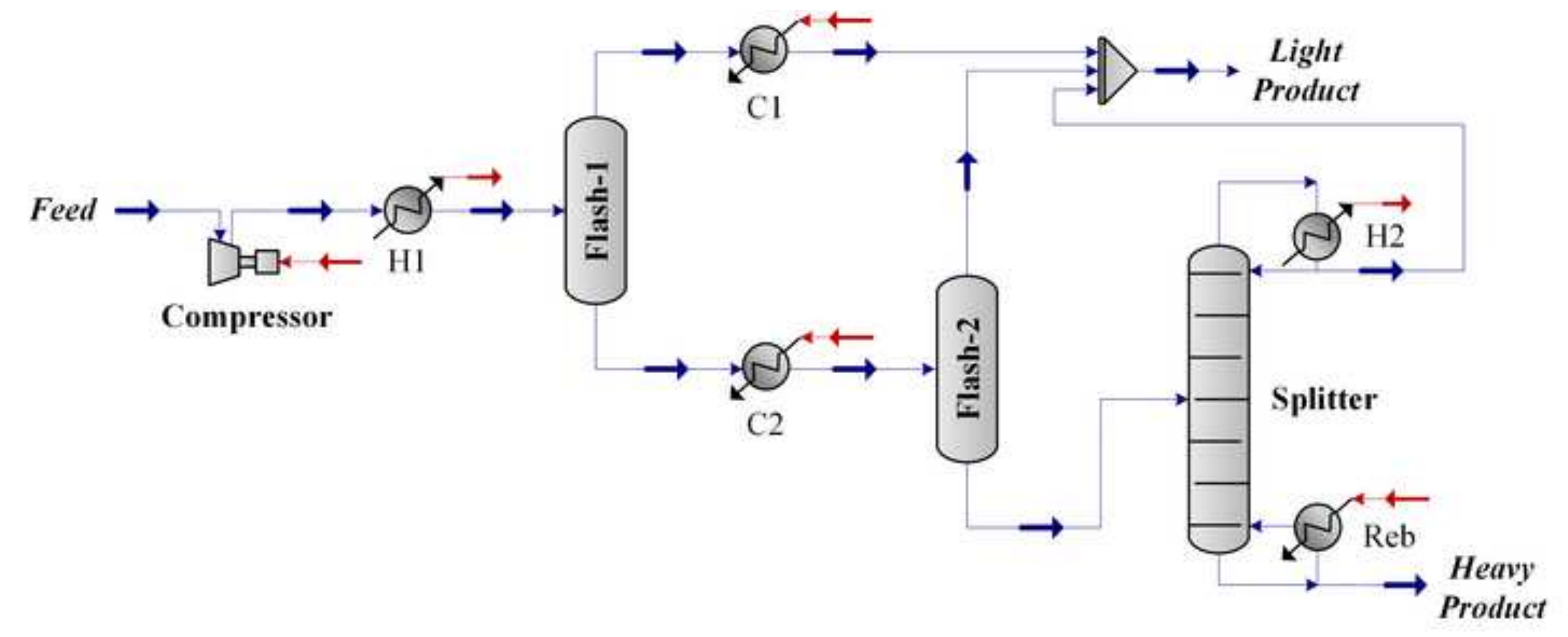




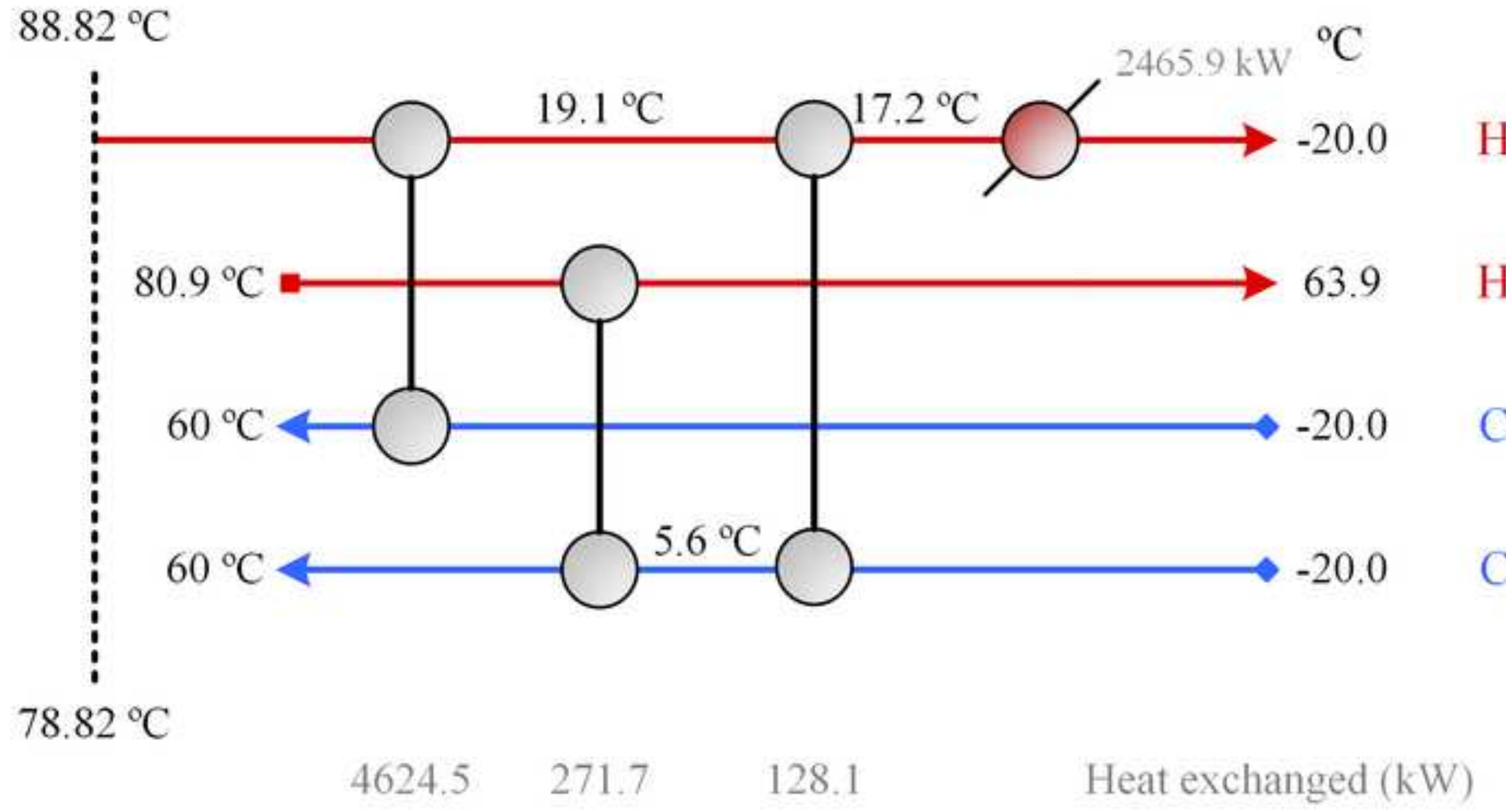

